\title{
Endometrial Regeneration and Conception Rate Following Oestrus Induction with Ovsynch Treatment in Normally Calved and RFM Treated Cows
}

\author{
C. Velladurai", R. Ezakial Napolean, M. Selvaraju, K.A. Doraisamy and \\ G.A. Balasubramaniam
}

\author{
Department of Veterinary Gynaecology and Obstetrics, Veterinary College and Research \\ Institute, Namakkal-2, Tamil Nadu, India \\ *Corresponding author
}

\begin{tabular}{|c|c|}
\hline \multicolumn{2}{|r|}{ A B S T R A C T } \\
\hline & \multirow{7}{*}{$\begin{array}{l}\text { Endometrial histopathology was studied in } 16 \text { cows at } 35-50 \text { days post-partum period } \\
\text { including } 8 \text { cows treated for RFM (Group I) and } 8 \text { normally calved cows (Group II) before } \\
\text { and after oestrus induction with Ovsynch treatment. In NC cows, the uterine endometrium } \\
\text { was intact. Multiple glandular acini and congestion were noticed. Uterine subendometrium } \\
\text { showed few glandular acini lined with single layer of epithelial cells. Solitary glandular } \\
\text { acini lined by multi layers of epithelial cells. Histopathology of the uterus in the RFM } \\
\text { affected cows before treatment reveals discontinuation of the endometrial epithelial lining. } \\
\text { Complete loss of epithelial lining associated with degenerative changes and atrophied } \\
\text { glandular acini and loss of epithelial cells in the endometrial glands. After treatment, NC } \\
\text { cows showed active proliferation of epithelial cells with intactness of endometrium. Uterus } \\
\text { showed normal architecture of subendometrium with glandular acini. The intact } \\
\text { endometrium with hyperplasia of endometrial glands was observed. The histological } \\
\text { changes in RFM affected cows after treatment were highly impressive. Proliferations of } \\
\text { epithelial lining of endometrium and engorged blood vessels with active glandular acini of } \\
\text { the endometrial glands are evident. The first service, second service and overall conception } \\
\text { rates observed were } 25.00,50.00 \text { and } 75.00 \text { and } 37.50,50.00 \text { and } 87.50 \text { per cent in Group I } \\
\text { and II, respectively. Hence it is concluded that increased conception rate after ovsynch } \\
\text { treatment in post-partum NC than the RFM affected cows positively correlated with the } \\
\text { well healthy endometrium lining and glandular development. }\end{array}$} \\
\hline & \\
\hline Endometrium, & \\
\hline $\begin{array}{l}\text { Conception rate, } \\
\text { Oestrus, Ovsynch, } \\
\text { Cows, RFM. }\end{array}$ & \\
\hline Article Info & \\
\hline $\begin{array}{l}\text { Accepted: } \\
\text { 10 September } 2017 \\
\text { Available Online: } \\
10 \text { November } 2017\end{array}$ & \\
\hline & \\
\hline
\end{tabular}

\section{Introduction}

The uterine endometrial biopsy technique was more useful in evaluating the endometrial and ovarian status in post-partum cows. Microscopically, during post-partum period the uterine lining epithelium was found to be normal with pseudo-stratified columnar type. Sub-epithelial diffuse haemorrhages, cellular infiltration in uterine stroma and stromal oedema were observed. Uterine glands were found dilated and filled with desquamated material. Cytoplasmic vacuolation in glandular epithelium and oedema of uterine glands were observed (Morrow, 1980). Uterine biopsy was a valuable diagnostic tool in identifying morphological alterations in the uterine endometrium (Prasad and Krishna, 2009). The endometrium of all mammals is richly endowed with glands that open on to the luminal surface. The endometrial glands secrete a variety of molecules, collectively 
termed as histotroph or uterine milk that is essential for maternal support of conceptus survival and growth in mammals (Gray et al., 2001). Pathak and Bansal (2012) observed that the endometrial glands were simple or branched tubular glands of which few were coiled distally. They were lined with simple columnar epithelium. These glands were more active during the follicular phase as compared to the luteal phase of the oestrous cycle. But the secretary activity was more pronounced during the luteal phase. Raja et al., (2012) reported that the histopathology of endometrium showed marked cellular changes of different degrees such as glandular hyperplasia, degenerative changes of the endometrium, cystic dilatation, mononuclear infiltration and perivascular fibrosis. Hence, the present investigation was formulated to study the effect of ovsynch treatment on endometrial regeneration and conception rate in RFM affected and normally calved cows.

\section{Materials and Methods}

At 35-50 days postpartum 8 cows treated (Group I) for retained fetal membranes (RFM) and 8 normally calved (NC) cows (Group II) were selected from Large Animal Gynaecology unit of Teaching Veterinary Clinical Complex, Veterinary College and Research Institute, Namakkal and from Veterinary Dispensaries, Tamil Nadu Cooperative Milk Producer Federation (TCMPF) Co-operative societies which are located in and around Namakkal district of Tamil Nadu for the study. They were supplemented orally with TANUVAS mineral mixture daily @ 3050 grams for 15 days. At the end of mineral mixture supplementation cows of both the groups were treated with ovsynch protocol. The protocol included administration of $10 \mu \mathrm{g}$ of GnRH intramuscularly $(2.5 \mathrm{ml}$, Buserelin acetate, Ovulanta ${ }^{\circledR}$, Vet Mankind, New Delhi) on the day of start of synchronization (day 0), $500 \mu \mathrm{g}$ of $\mathrm{PGF}_{2} \alpha$ intramuscularly $(2 \mathrm{ml}$,
Cloprostenol, Pragma ${ }^{\circledR}$, INTAS, Ahmedabad) seven days later (day 7), another $10 \mu \mathrm{g}$ of GnRH intramuscularly $48 \mathrm{~h}$ after $\mathrm{PGF}_{2} \alpha$ (day 9) and timed artificial insemination (TAI) was done at 16 to 18 hours after the second GnRH injection (day 10).

Endometrial biopsy was taken from the all experimental animals (i) at the time of animal selection and (ii) at AI, to study the histopathological changes of the endometrium before and after treatment. Albuchin's uterine biopsy catheter (Plate 1a and 1b) was used to obtain endometrial biopsy samples as per the technique followed by Palanisamy (2012) with slight modifications. The closed, sterilized biopsy catheter was introduced into the uterus adopting aseptic technique. The biopsy catheter was advanced into one of the uterine horns of uterus and the catheter was opened. The uterine wall was pressed with the thumb against the opening of the catheter. The catheter was closed, rotated and retracted slowly. Slight pressure was applied against catheter to prevent haemorrhage before retracting the instrument. A piece of endometrium was released from the cutting edge of the catheter into a vial containing Bouin's fluid and stored for 24 hours and processed by routine paraffin technique and stained with haematoxyline and eosin as per technique described by Bancroft and Gamble (2008). Conception rate was calculated as percentage of animals that conceived to AI at induced estrus in both the groups. Pregnancy was confirmed by rectal palpation at 60 days post insemination.

\section{Results and Discussion}

The histopathological changes of uterine endometrial lining and proliferation of endometrium in RFM affected cows before is presented in Plate 2. The histopathological study on the uterus after treatment in the RFM affected groups are presented in Plate 3. The 
histopathology of endometrium of NC cows before treatment is presented in Plate 4 . The histopathology of endometrium of NC cows after treatment is presented in Plate 5.

Histopathology of the uterus in the RFM affected cows before treatment reveals discontinuation of the endometrial epithelial lining. Complete loss of epithelial lining associated with degenerative changes and atrophied glandular acini and loss of epithelial cells in the endometrial glands before oestrus induction indicated the probable damage caused by RFM which is not noticed in the NC cows. However, after treatment proliferations of epithelial lining of endometrium and engorged blood vessels with active glandular acini of the endometrial glands are evident in RFM affected cows. These findings were in accordance and comparable with the reports of Prasad and Krishna (2009) in cows affected with RFM which showed clear regeneration of endometrium and its glandular acini after treatment. In the case of untreated control cows of the group II, the endometrial lining and glandular acini remained functional and unchanged before and after treatment without any degenerative changes or hyper plastic changes and it was in accordance with the findings of Singh et al., (1997) in buffaloes and Prasad and Krishna (2009) in cows.

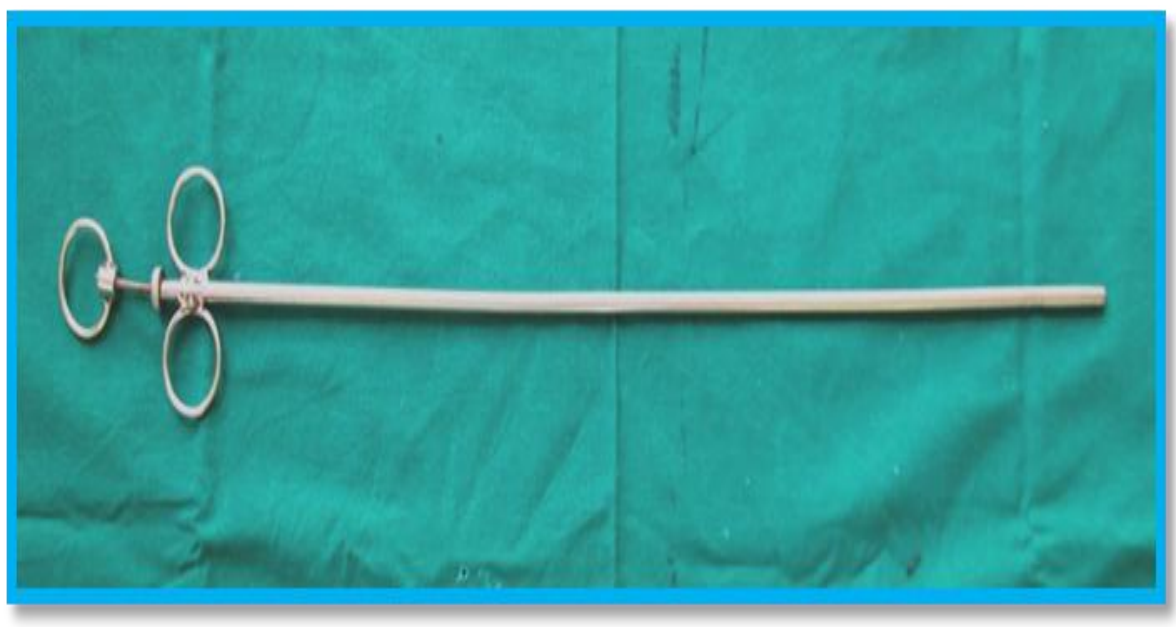

Plate.1a Albuchin's uterine biopsy catheter-with closed cut edge

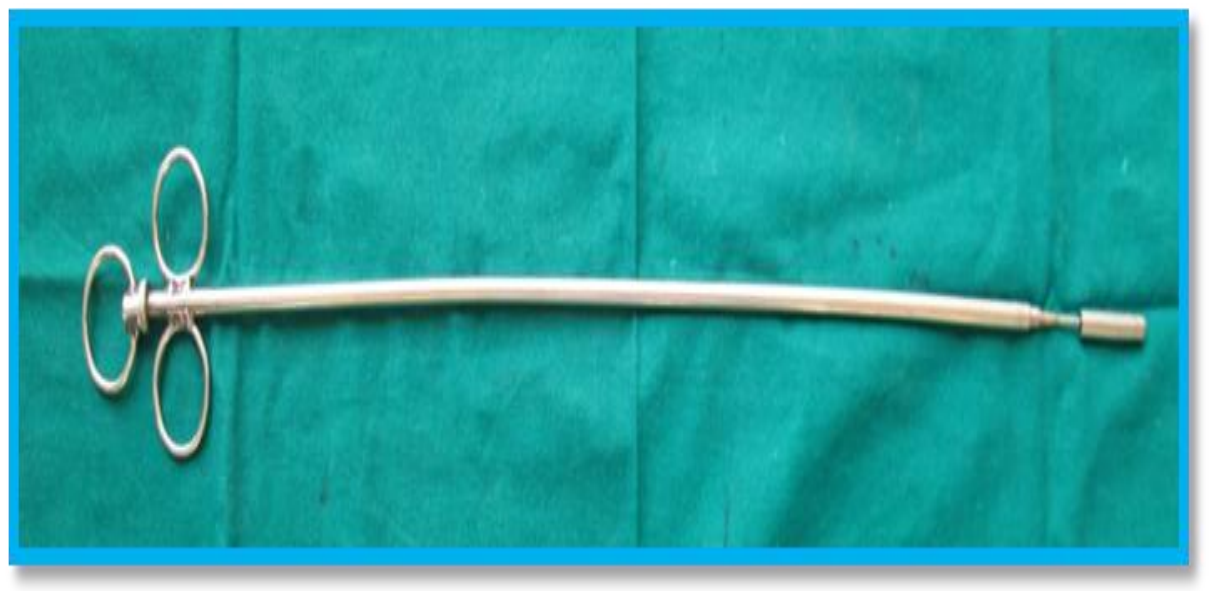

Plate.1b Albuchin's uterine biopsy catheter-with open tissue grasper 
Plate.2 Histopathology of endometrium in RFM affected cows - Before treatment

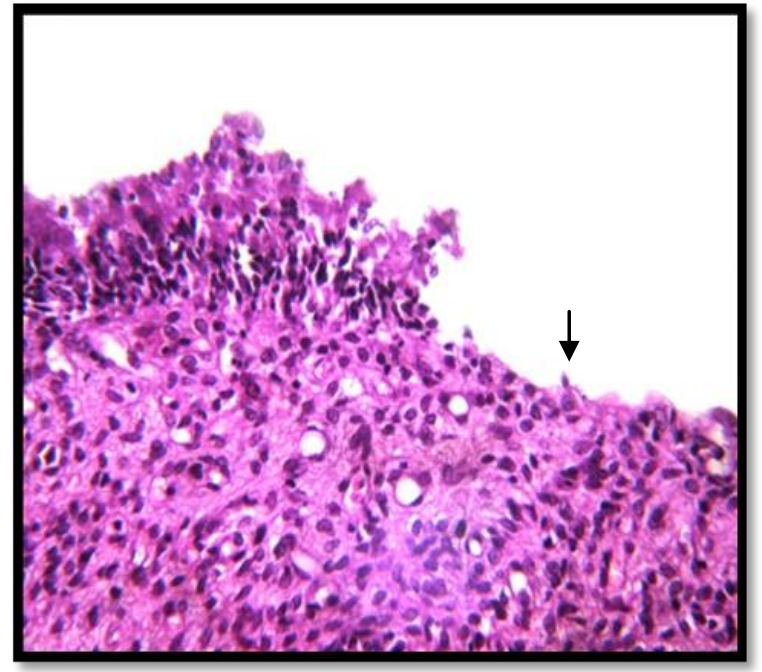

Uterus showing the discontinuation in endometrial epithelial linings.

\section{H\&E 400x}

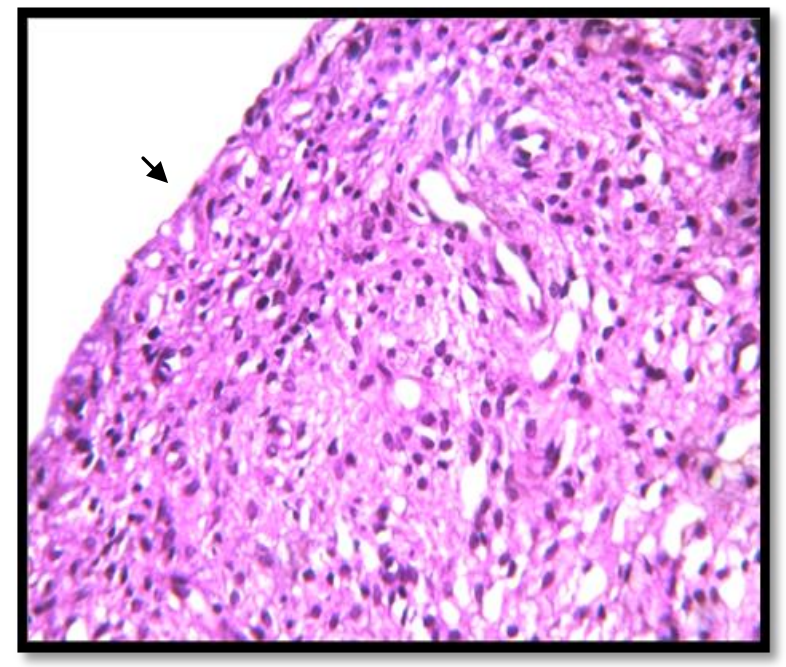

Uterus showing the complete loss of epithelial linings associated with degeneration of endometrium.

H\&E 400x

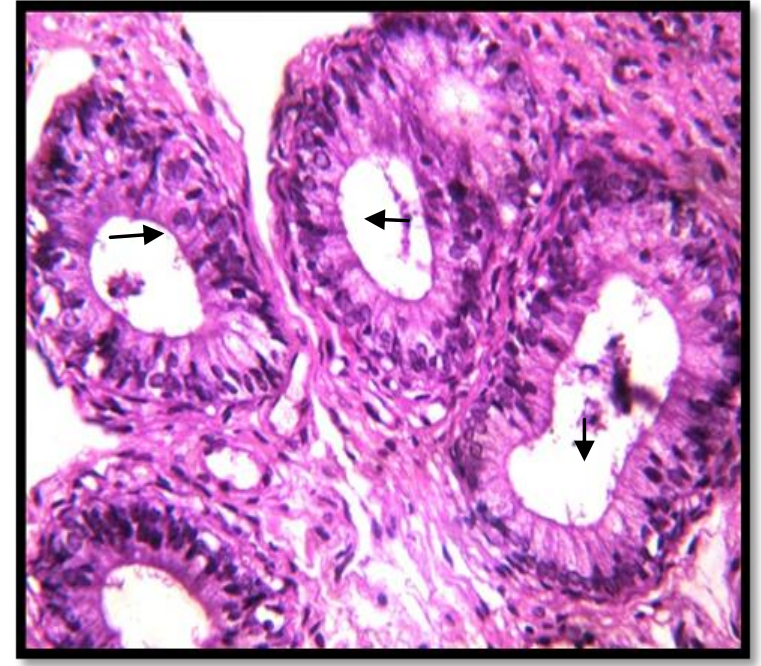

Uterus showing the active proliferation of epithelial cells lining the glandular acini.

H\&E 400x

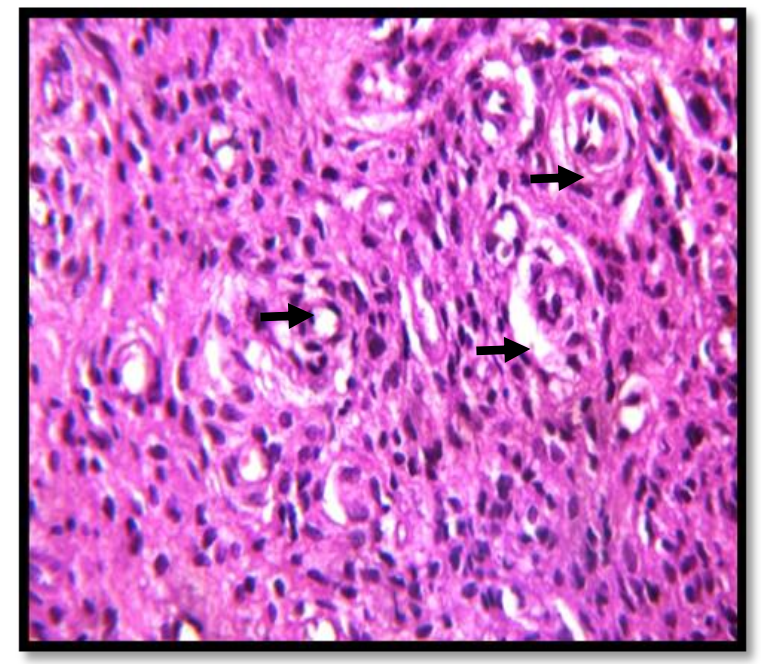

Uterus showing the atrophied glandular acini with loss of epithelial cells.

\section{H\&E 400x}


Plate.3 Histopathology of endometrium in RFM affected cows - After treatment

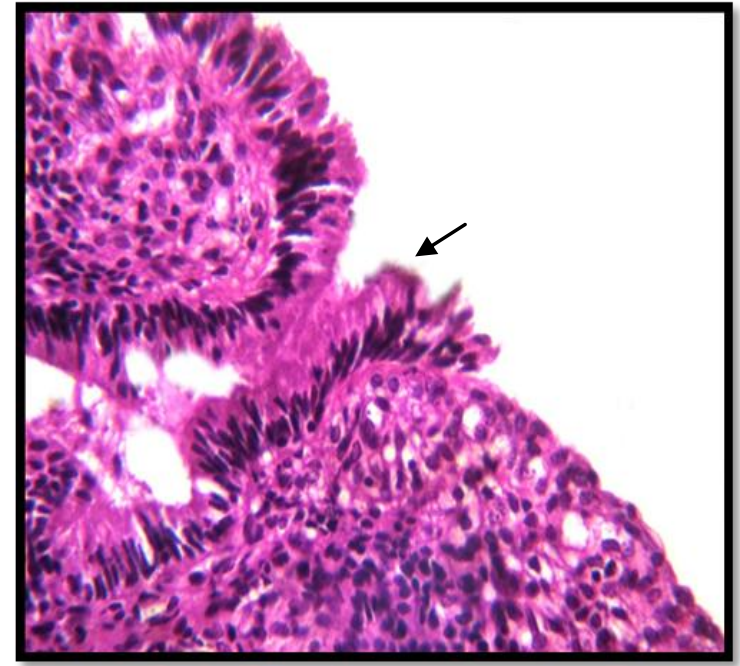

Uterus showing the active proliferation of epithelial cells lining the subendometrium.

H\&E 400x

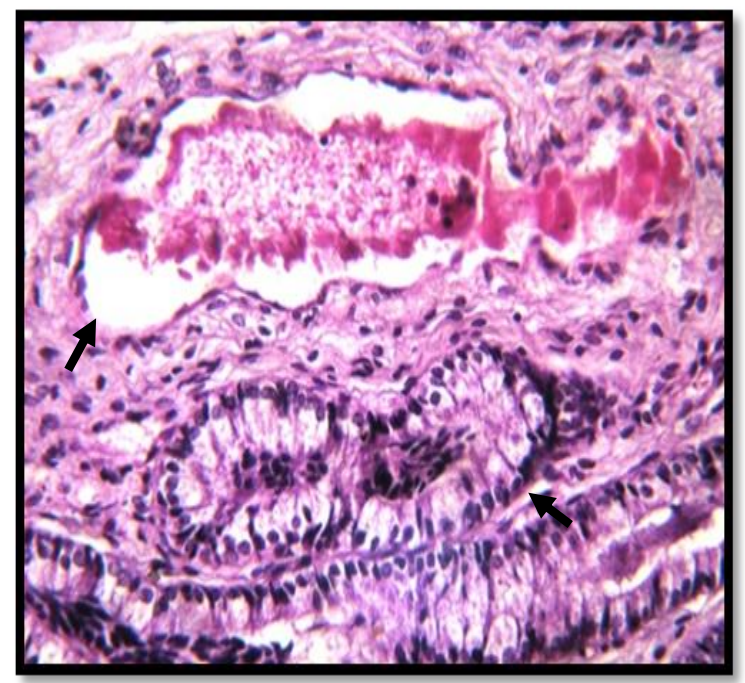

Uterus showing the glandular acini lined with prominent epithelial cells and engorged blood vessel.

H\&E 400x

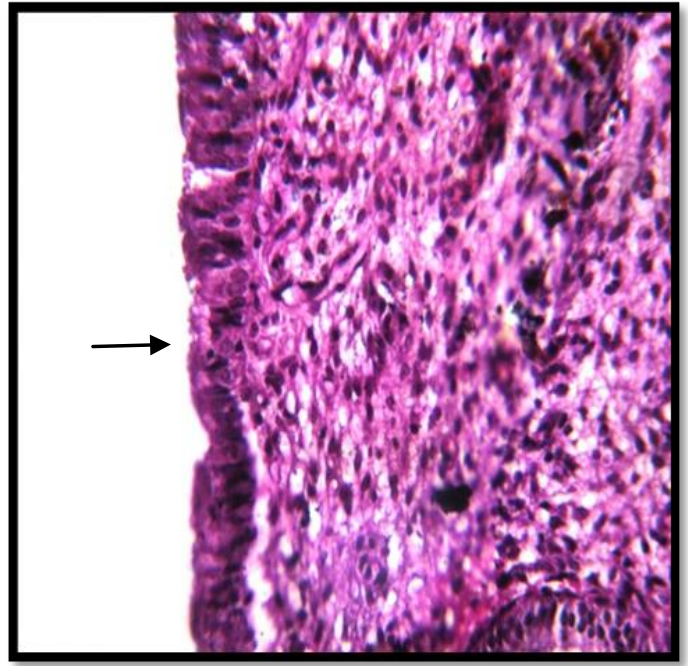

Uterus showing intact endometrium with proliferating epithelial cells.

H\&E 400x

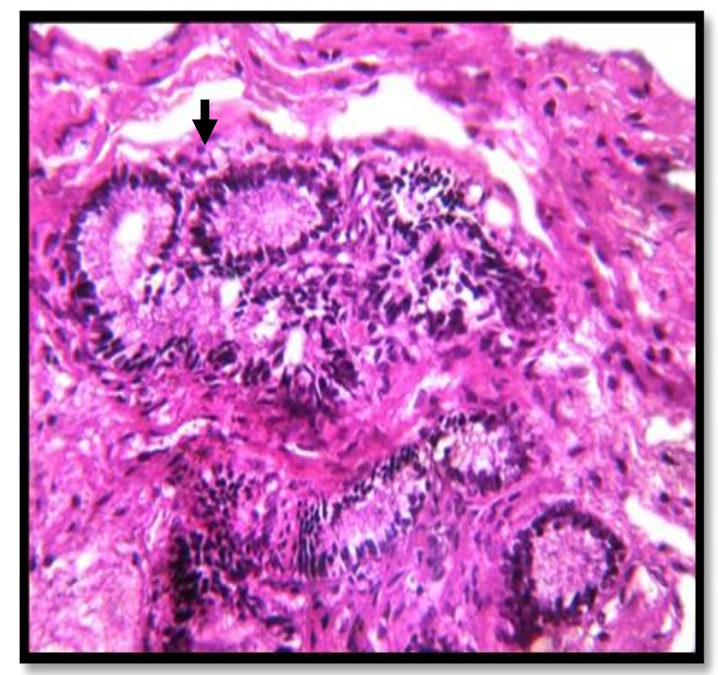

Uterus showing the multiple glandular acini with hyperplasia of lining epithelium.

H\&E 200x 
Plate.4 Histopathology of endometrium in NC cows - Before treatment

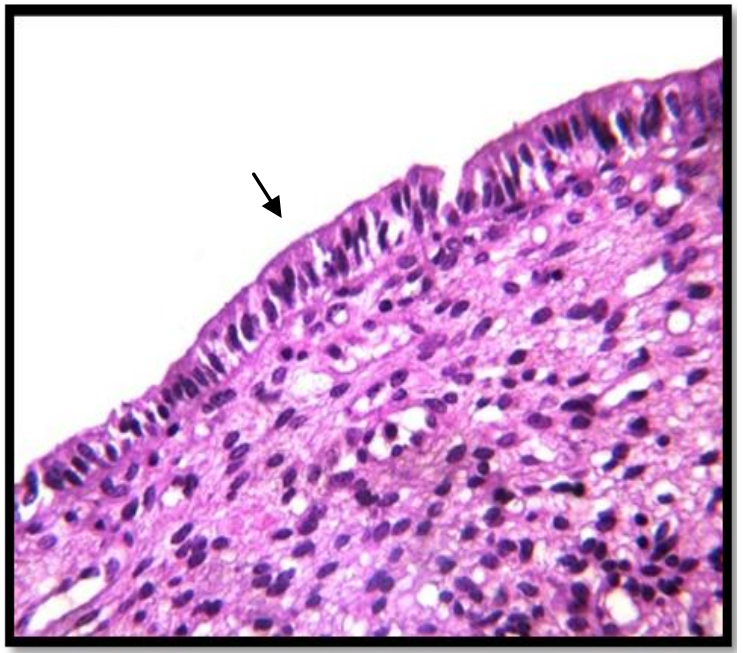

Normal uterus showing the intact endometrium.

H\&E 400x

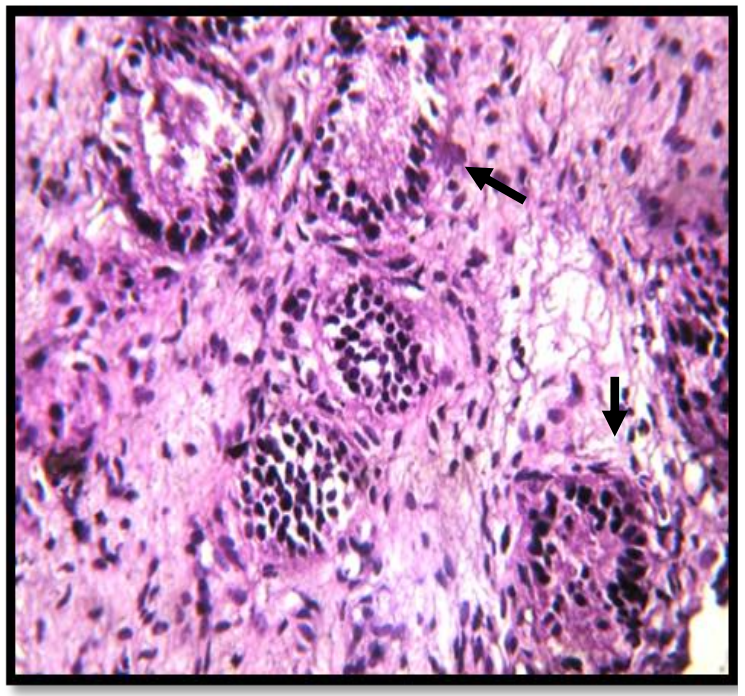

Uterine subendometrium showing few glandular acini lined with single layer of epithelial cells.

H\&E 400x

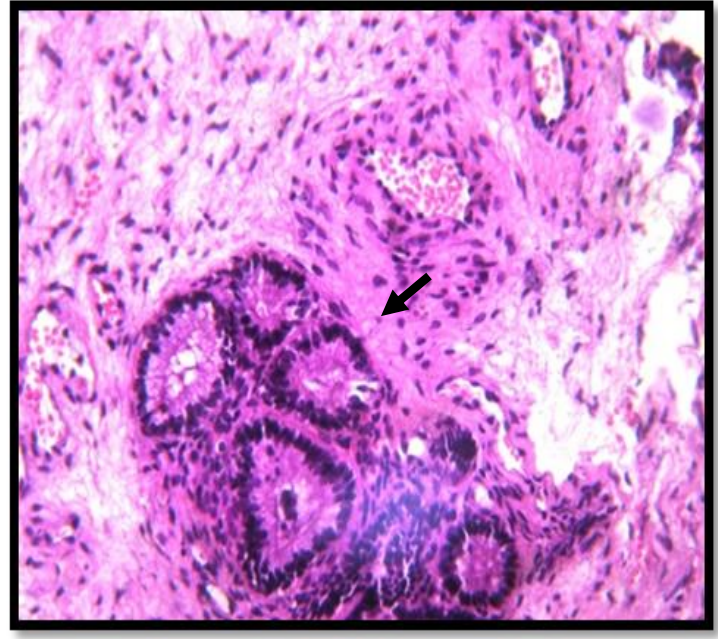

Normal uterus showing multiple glandular acini and congestion.

H\&E 200x

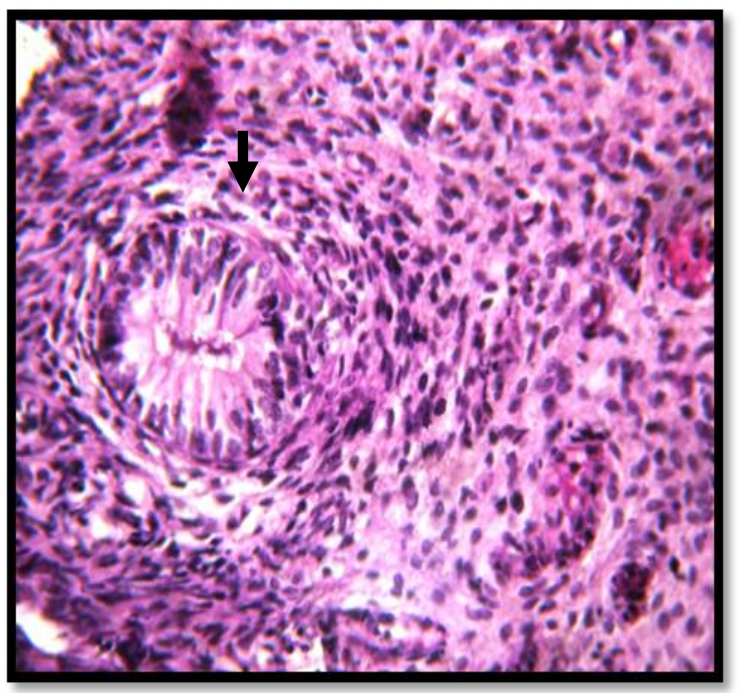

Uterus showing a solitary glandular acini lined by multi layers of epithelial cells.

H\&E 400x 


\section{Plate.5 Histopathology of endometrium in NC cows - After treatment}

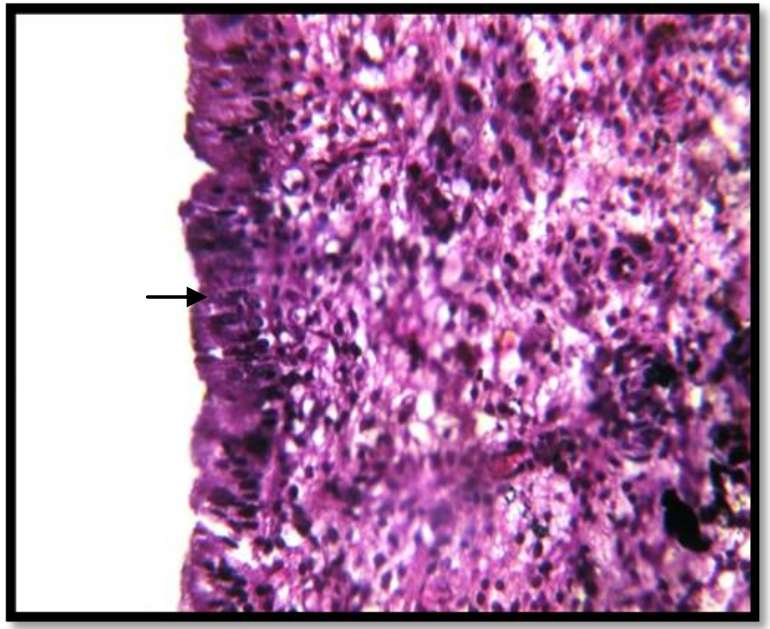

Uterus showing the proliferation of epithelial cells with intactness of endometrium.

H\&E 400x

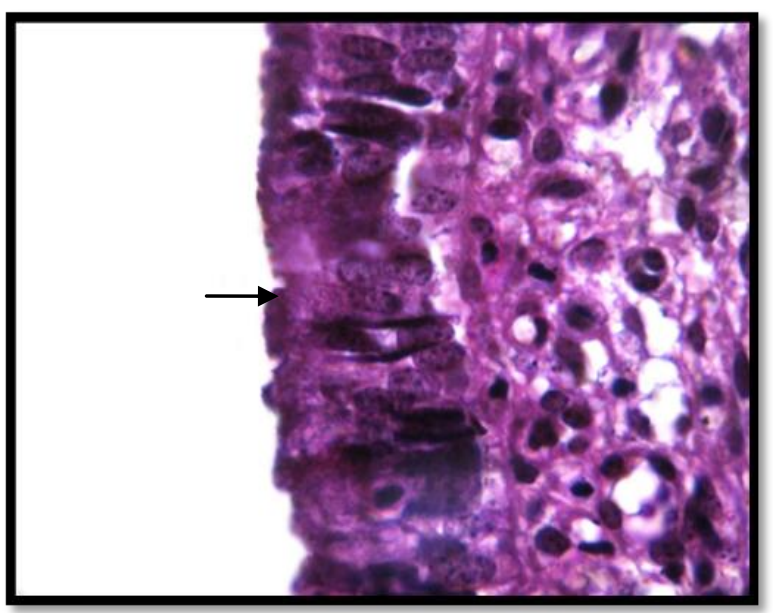

Uterus showing hyperplasia of epithelial cells lining endometrium.

H\&E 1000x

Endometrial regeneration was evident and resumption of ovarian activity resulted in the oestrus induction in RFM affected cows which was well supported by the findings of Prasad and Krishna (2009) who proved that uterus had the powerful system of natural repair and recovery with the stimulated uterine defence mechanism. The first service,

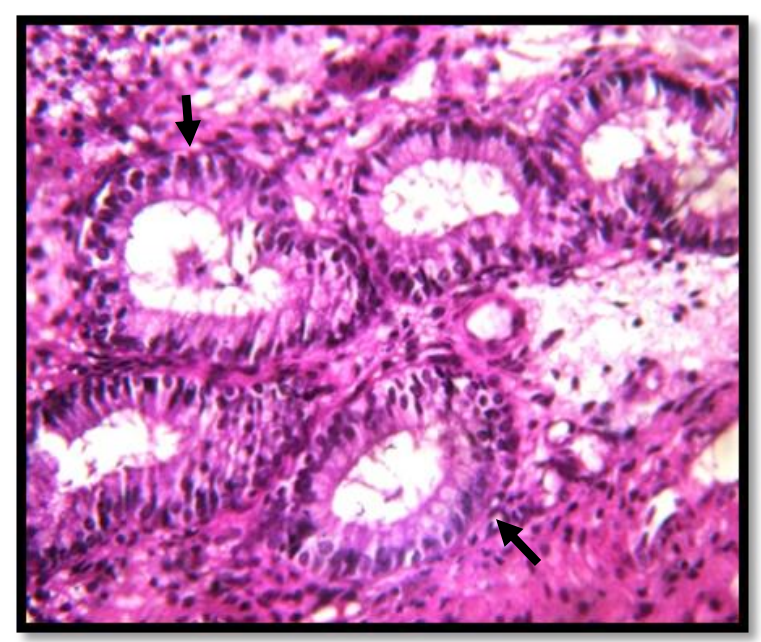

Uterus showing the active proliferation of epithelial cells lining the glandular acini.

H\&E 400x

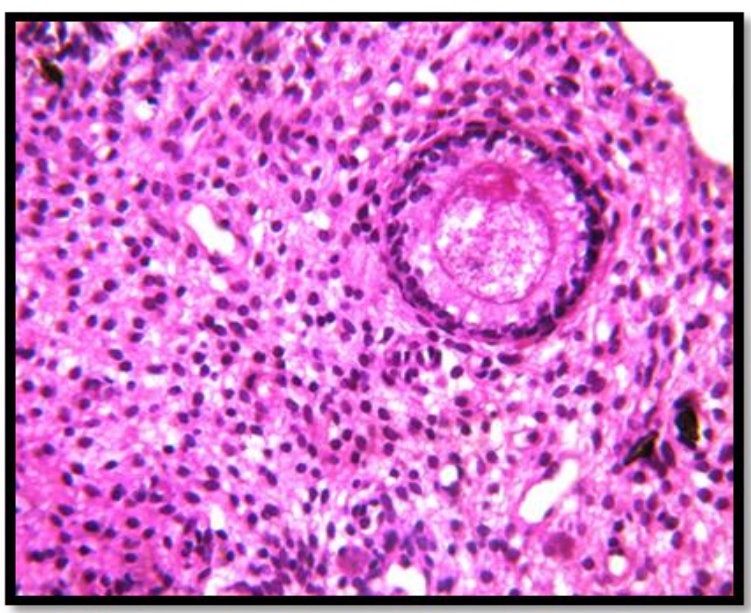

Uterus showing normal architecture of subendometrium with glandular acini.

H\&E 400x

second service and overall conception rates observed in this study were $25.00,50.00$ and 75.00 and $37.50,50.00$ and 87.50 per cent in group I and II, respectively. The result revealed that oestrus induction with ovsynch protocol at 50 to 65 days postpartum in cows yielded 87.50 and 75.00 per cent overall conception rates in $\mathrm{NC}$ and RFM affected 
cows, respectively. It was in concurrence with the findings of Pursley et al., (1997). Greater conception rate achieved in the present study was due to the commencement of ovsynch at appropriate stage of the oestrous cycle which would have induced preovulatory LH surge and ovulation as described by Moreira et al., (2000).The increasing trend in the conception rate from the first service to that of the second service could be attributed to the sensitization of the brain receptors by progesterone and good response to the ovarian estrogen from a large Graafian follicle of $>10 \mathrm{~mm}$ diameter followed by ovulation and formation of functional corpus luteum establishing pregnancy.

\section{References}

Bancroft, J. D., and Gamble, M. 2008. Theory and practice of histological techniques. $6^{\text {th }}$ ed., Churchill Livingston, Elsevier, Philaelphia.

Gray, C. A., K. M. Taylor, W. S. Ramsey, J. R. Hill, F. W. Bazer, F. F. Bartol and Spencer, T. E. 2001. Histomorphology of the endometrial gland of buffalo. Biol. Reprod., 64: 1608.

Moreira, F., R. L. De la Sota, T. Diaz and Thatcher, W. W. 2000. Effect of day of the estrous cycle at the initiation of a timed artificial insemination protocol on reproductive responses in dairy heifers. J. Anim. Sci., 78: 1568-1576.

Morrow, D. A., 1980. Current therapy in theriogenology. W.B. Saunders Company Philadelphia, London. Pp. 7279.

Palanisamy, M., 2012. Efficacy of immunomodulators, Lugol's iodine and prostaglandin $\mathrm{F}_{2} \alpha$ in the treatment of post-partum endometritis in cows. Ph.D., thesis submitted to Tamil Nadu Veterinary and Animal Sciences University, Chennai.

Pathak, D., and Bansal, N. 2012. Histomorphology of the endometrial gland of Buffalo. Indian Vet. J., 89: 2528.

Prasad, B. C., and Krishna, K. M. 2009. Effect of RFM on histomorphology of uterine endometrium in cross bred cows. Tamil Nadu J. Vet. Anim. Sci., 5: 164-166.

Pursley, J. R., M. R. Kosorok and Wiltbank, M. C. 1997. Reproductive management of lactating dairy cows using synchronization of ovulation. J. Dairy Sci., 80: 301-306.

Raja, S., T. G. Devanathan, K. Kulasekar, N. Pazhanivel and Balachandran, C. 2012. Whiteside test and endometrial biopsy for diagnosis of endometritis in repeat breeding cows. Indian J. Anim. Reprod., 33: $56-58$.

Singh, J., R. A. Pierson and Adams, G. P. 1997. Ultrasound images attributes of the bovine corpous luteum: structural and functional correlates. J. Reprod. Fertil, 109: 35-44.

\section{How to cite this article:}

Velladurai, C., R. Ezakial Napolean, M. Selvaraju, K.A. Doraisamy and Balasubramaniam, G.A. 2017. Endometrial Regeneration and Conception Rate Following Oestrus Induction with Ovsynch Treatment in Normally Calved and RFM Treated Cows. Int.J.Curr.Microbiol.App.Sci. 6(11): 970-977. doi: https://doi.org/10.20546/ijcmas.2017.611.114 